\title{
EFFECT OF DEPTH TO THICKNESS RATIO AND LENGTH TO DEPTH RATIO ON HOLLOW SECTION ALUMINIUM TUBES FILLED WITH SELF COMPACTING CONCRETE
}

\author{
Gopinatha Nayak $^{1}$, Kiran K. Shetty ${ }^{2}$, Soltan Abdalla ${ }^{3}$ \\ ${ }^{1}$ Associate professor, Department of Civil Engineering, Manipal Institute of Technology/Manipal University, Karnataka, \\ India \\ ${ }^{2}$ Associate Professor (senior scale), Department of Civil Engineering, Manipal Institute of Technology/Manipal \\ University, Karnataka, India \\ ${ }^{3}$ P.G student, Department of Civil Engineering, Manipal Institute of Technology/Manipal University, Karnataka, India
}

\begin{abstract}
An experimental investigation on aluminum hollow section tubes is presented in this paper. Axial compression tests were conducted to investigate the effect of depth to thickness ratio $(D / t)$ and length to depth ratio $(L / D)$ on the composite aluminum tubes which were filled with self-compacting concrete (SCC). The behavior, compatibility and strength limits were studied. An M25 grade of concrete was used. Tubes were 6063-T6 aluminum heat treated alloy extrusions with 214MPa yield strength. The depth to thickness ratio for the tubes ranged from 12 to 33.3. Length to depth ratio $(L / D)$ varied from 3 to 10 to include all modes of failure. The column strength vs. load axial shortening graphs were plotted and failure modes were presented. Results have shown that combination of selfcompacting concrete and Aluminum tubes is a good choice for construction and can withstand a considerable amount of load.
\end{abstract}

Keywords: Self compacting concrete, Aluminum hollow section tubes

\section{INTRODUCTION}

Corrosion is one of the main issues when it comes to using steel in construction. If there is a way to substitute steel with other material which can take the same loads but solve that problem it would be of a great use. Aluminum has been neglected by Structural engineers for the myth that it is a week material, which is true if it is in its pure form. Aluminum can be mixed with certain elements and the results would be a very strong alloy that resists rust and have one third of the steel weight. Aluminum alloys varies depending on the application they are being used on. It's a material that can be tailored according to ones need. Strength combined with stiffness allows the designer to cut down member sizes and hence saving in the overall cost of the building plus it is a green material in terms of manufacturing and recycling.

Experimental investigation of normal Concrete-filled aluminum circular hollow section (CHS) column was reported by Zhou and Young [1]. A series of tests were conducted to investigate the effect of the geometric dimension of aluminum CHS and concrete strength on the behavior and strength of concrete-filled aluminum CHS stub columns. The structural performance of the concrete-filled aluminum CHS stub columns was investigated using different concrete cylinder strengths of 40, 70 and $100 \mathrm{MPa}$. The CHS tubes were fabricated by extrusion using 6061-T6 heat-treated aluminum alloy having nominal $0.2 \%$ proof stress of $240 \mathrm{MPa}$. The D/t of the CHS tubes ranged from 9.7 to 59.7. The column lengths were chosen so that the length-to-diameter ratio generally remained at a constant value of 3 to prevent overall column buckling. The concrete-filled aluminum CHS specimens were subjected to uniform axial compression. The column strengths, load-axial shortening relationship, load-axial strain relationship and failure modes of columns were presented. The test strengths were compared with the design strengths calculated using the American specifications and Australian/New Zealand standards for aluminum and concrete structures. It is shown that the design strengths are generally conservative for concrete-filled aluminum CHS stub columns.

It is well known that concrete-filled steel composite columns have the advantages of high-bearing capacity and ductility, easy construction and cost saving [2].Ji-Hua and young [3] made a comparison between different types of alloys circular hollow tubes with different geometries to investigate the effect of welding on the tubes ultimate capacity. Han and Yao [4] presented a paper in an attempt to study the possibility of using thin-walled HSS columns filled with SCC and to investigate the influence of concrete compaction methods on the member capacities of the composite columns. Circular hollow section (CHS) tube provides much better confining effect to concrete core, especially, when the diameter- tothickness (D/t) ratio is small compared with SHS and RHS 
tubes [5]. Zhou and Young [6] reported that square tubes failed by splitting before reaching the ultimate capacity of the columns hence was inefficient.

The purpose of this paper is to investigate the structural behavior and strength of aluminum concrete composite columns and to check the effect of diameter to thickness ratio and length to thickness ratio. A series of tests were performed on composite columns. Columns were subjected to axial compression loading. Length to diameter ratio varied from 3 to 10 to include all types of failure. Failure modes and strengths were noted.

\section{EXPERIMENTAL INVESTIGATION}

\subsection{Concrete Properties}

An M25 grade self-compacting concrete was produced by Anil Kumar [7] using commercially available materials. The mix was optimized using EFNARC [8] recommendations. The Mix proportions were as follow: cement: $367.5 \mathrm{~kg} / \mathrm{m} 3$, fly ash: $332.5 \mathrm{~kg} / \mathrm{m} 3$; water: $212.8 \mathrm{~kg} / \mathrm{m} 3$; Fine Aggregate: 632.35 $\mathrm{kg} / \mathrm{m} 3$; coarse aggregate: $696.45 \mathrm{~kg} / \mathrm{m} 3$ and super plasticizer: $3.59 \mathrm{~kg} / \mathrm{m} 3$.

Table-1: Aluminum tubes Geometrical Properties

\begin{tabular}{|c|c|c|c|c|c|}
\hline & Diameter $(\mathrm{mm})$ & Tube Thick (mm) & Length (mm) & $\mathrm{L} / \mathrm{D}$ & $\mathrm{D} / \mathrm{t}$ \\
\hline \multirow[t]{6}{*}{ G1 } & 38.1 & 3.17 & 115 & 3 & 12.0 \\
\hline & 38.1 & 3.17 & 115 & 3 & 12.0 \\
\hline & 38.1 & 3.17 & 153 & 4 & 12.0 \\
\hline & 38.1 & 3.17 & 229 & 6 & 12.0 \\
\hline & 38.1 & 3.17 & 305 & 8 & 12.0 \\
\hline & 38.1 & 3.17 & 381 & 10 & 12.0 \\
\hline \multirow[t]{6}{*}{ G2 } & 50.8 & 3.17 & 153 & 3 & 16.0 \\
\hline & 50.8 & 3.17 & 153 & 3 & 16.0 \\
\hline & 50.8 & 3.17 & 203 & 4 & 16.0 \\
\hline & 50.8 & 3.17 & 305 & 6 & 16.0 \\
\hline & 50.8 & 3.17 & 407 & 8 & 16.0 \\
\hline & 50.8 & 3.17 & 508 & 10 & 16.0 \\
\hline \multirow[t]{6}{*}{ G3 } & 63 & 3.17 & 189 & 3 & 19.9 \\
\hline & 63 & 3.17 & 189 & 3 & 19.9 \\
\hline & 63 & 3.17 & 252 & 4 & 19.9 \\
\hline & 63 & 3.17 & 378 & 6 & 19.9 \\
\hline & 63 & 3.17 & 504 & 8 & 19.9 \\
\hline & 63 & 3.17 & 630 & 10 & 19.9 \\
\hline \multirow[t]{5}{*}{ G4 } & 100 & 3 & 300 & 3 & 33.3 \\
\hline & 100 & 3 & 300 & 3 & 33.3 \\
\hline & 100 & 3 & 400 & 4 & 33.3 \\
\hline & 100 & 3 & 600 & 6 & 33.3 \\
\hline & 100 & 3 & 800 & 8 & 33.3 \\
\hline
\end{tabular}


Max size of coarse aggregate was $12 \mathrm{~mm}$. Compression tests were conducted for $150 \mathrm{~mm}$ standard cubes and cube strength was $25 \mathrm{MPa}$ for 7 days and $34.4 \mathrm{MPa}$ for 28 days.

\subsection{Test Specimens}

Geometric properties of specimens are shown in table-1. Twenty four columns were tested under axial compression. Tubes were made of aluminum extrusion 6063-T6 heat treated alloy. Tubes were divided into 4 groups, each group had different diameters as follow: G1: $38.1 \mathrm{~mm}$; G2: $50.8 \mathrm{~mm}$; G3 $63 \mathrm{~mm}$ and G4 $100 \mathrm{~mm}$ with a wall thickness of $3.17 \mathrm{~mm}$ for Group 1,2 and 3 and a thickness of $3.00 \mathrm{~mm}$ for group 4 . D/t was $12,16,19.9$ and 33.3 for the groups respectively.

\subsection{Columns Testing}

A total number of 24 tubes were tested. Concrete was filled into the tubes and let to set. Columns were tested at concrete cube strength of 28.1MPa. Both end surfaces of columns were checked for excess concrete and leveled by a filing tool to make sure that the concrete and the aluminum tube edge were in one level for a uniform load application with full contact with the entire surface.

Columns were axially tested on an axial compression machine with a capacity of 100T. End conditions were assumed to be fixed. A dial gauge was used to measure the vertical displacement. Load vs. deflection graph was plotted and failure mode was noted. Figure-1 shows the test setup.

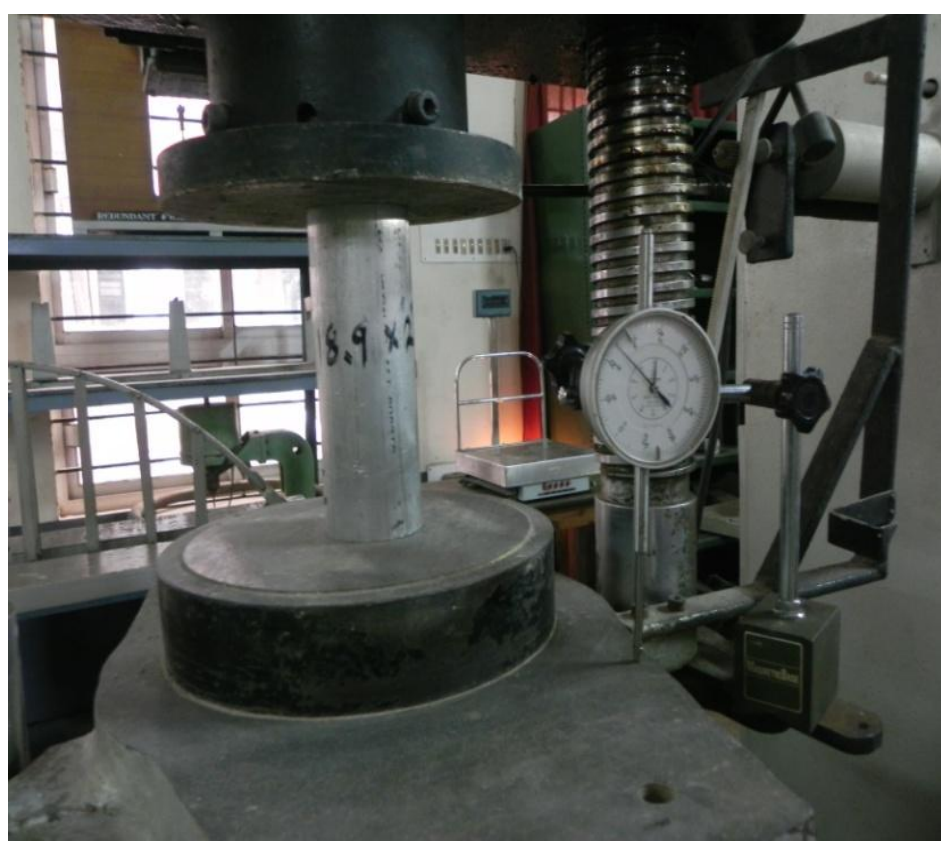

Fig-1: Column axial testing

\section{RESULTS}

Table (2) shows strength of concrete filled and empty tubes. Pal represents the strength of aluminum tube without infill. Pco represent the strength of the tube with infill. The addition of concrete has made a significant contribution in increasing the column capacity; the capacity increased by $50 \%$ for G1 and went on increasing up to $200 \%$ for G4. Load- axial shorting graph for Group 1 and 4 is shown in Fig (2) and Fig (3) respectively. The "E" prior to the group number indicates that the tube is without infill and the number following the group number represents the L/D. It can be observed from the graphs that the tubes with infill had a good amount of initial stiffness. Columns didn't have a clear yield point therefore a $2 \%$ proof stress can be used to obtain the yield point. The increase in L/D led to a decrease in strength but this effect becomes almost negligible with higher values of $\mathrm{D} / \mathrm{t}$.

Figure (4) shows the failure of columns. All the columns failed in a ductile manner. Failure modes were classical shear for tubes of L/D 3, 4 and 6. Columns with L/D of 8 and 10 failed with buckling.

Table-2: Test Results of Composite Columns

\begin{tabular}{|l|l|l|l|}
\hline Group & Pal (KN) & Pco (KN) & Pco/ Pal \\
\hline G1 & 83.39 & 122.63 & 1.471 \\
\hline G2 & 112.8 & 181.49 & 1.609 \\
\hline G3 & 83.39 & 191.3 & 2.294 \\
\hline G4 & 181.49 & 539.55 & 2.973 \\
\hline
\end{tabular}

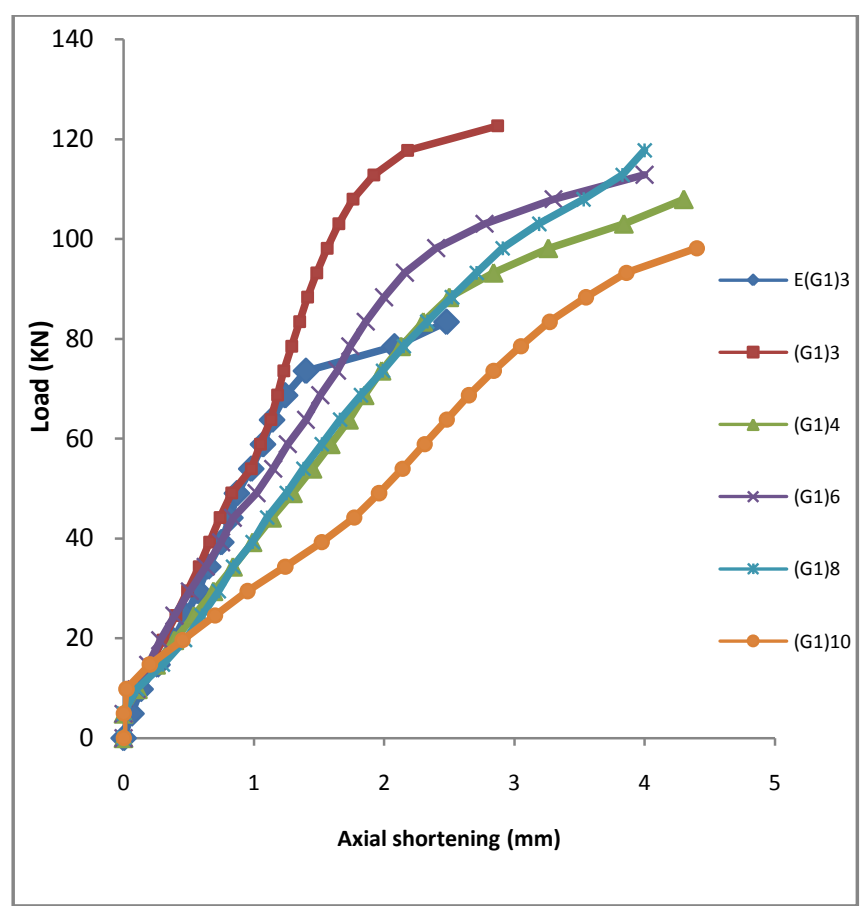

Fig-2: Load vs. axial shortening, G1 columns 


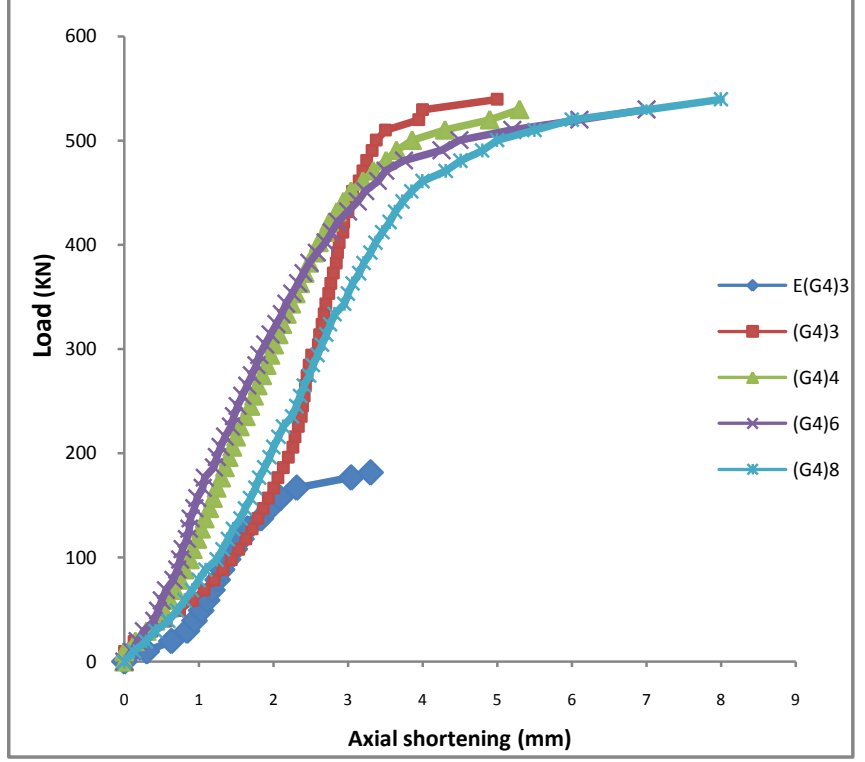

Fig-3: Load vs. axial shortening, G4 columns

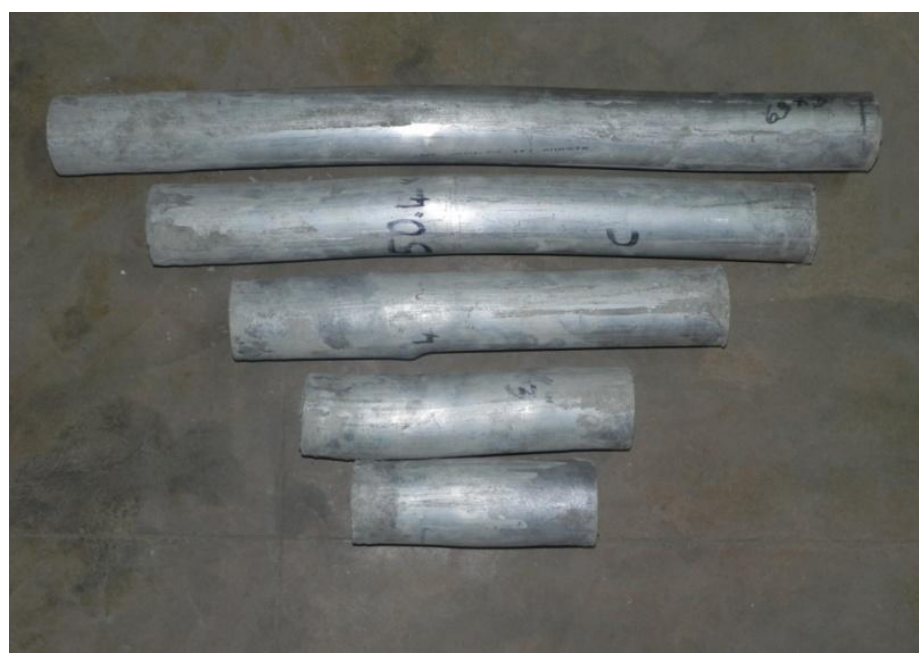

Fig-4: Failure modes

\section{CONCLUSIONS}

Twenty four specimens were tested and load-axial shortening relationship was obtained along with failure modes. Based on the results the following can be concluded; Aluminum tubes provided a good support to the concrete core, which lead to an increase in ultimate strength. The effect of $\mathrm{L} / \mathrm{D}$ in lowering the ultimate capacity of the columns becomes very less in high values of D/t. Stocky columns are more practical in case of aluminum columns. Ratio of strength of aluminum tubes to composite columns varied from 1.47 to 2.9. Failure modes for columns with slenderness of 3,4 and 6 were by shear while failure of columns with slenderness of 8 and 10 was by buckling.

\section{REFERENCES}

[1] Zhou F, Young B. Concrete-filled Aluminum circular hollow section column tests. Thin-Walled Structures 2009; 47: 1272-80.

[2] Knowles R B, Park, R. Strength of concrete filled steel tubular columns. Journal of Structural Engineering, ASCE 1969; 95(12):2565-87.

[3] Ji-Hua, Young. Experimental investigation of aluminum alloy circular hollow section columns. Engineering Structures 2006; 28:207-15

[4] Lin-Hai Han, Gua-Huang Yao. Experimental behavior of thin-walled hollow structural steel (HSS) columns filled with self-consolidating concrete (SCC). ThinWalled Structures 2004; 42:1357-77

[5] Hu HT, Huang CS, Wu MH, Wu YM. Nonlinear analysis of axially loaded concrete-filled tube columns with confinement effect. Journal of Structural Engineering, ASCE 2003; 129(10):1322-9.

[6] Zhou F, Young B. Tests of concrete-filled Aluminum stub columns. Thin-Walled Structures 2008; 46:57383.

[7] Anil Kumar M. Self-compacting concrete using recycled aggregate. MTech thesis, Manipal University; 2008.

[8] The European Guidelines for Self-Compacting Concrete Specification, Production and Use. EFNARC; 2005. 